\title{
OPINIÃo
}

\section{O PAPEL DO PSICÓLOGO DA SAÚDE FRENTE ÀS DEMANDAS SOCIAIS: UMA REFLEXÃO A PARTIR DA RELAÇÃO ENTRE PRÁTICA E TEORIA}

\author{
Roseane Chisthina da Nova Sá(1) \\ Roberta Lima de Azevedo(2)
}

Sabe-se que frente aos encontros e desencontros no âmbito da saúde a Psicologia Social emergiu como uma das ferramentas de trabalho junto às demais áreas do conhecimento. Ao passo que com a dissolução do modelo biomédico, surgiu uma nova representação da saúde e concomitantemente da doença e do doente.

Este artigo tem como escopo suscitar reflexões acerca do papel do psicólogo frente às demandas sociais emergentes, abrangendo o processo saúde-doença, a partir de temáticas que permeiam o campo da Psicologia e da Saúde Coletiva, levando em consideração o papel da família e o processo de aculturação.

Viajando pela história da Psicologia, percebe-se que tanto a prática profissional como acadêmica / científica desse campo do saber foi sendo edificada no elitismo social, no modelo biomédico, excluindo demandas carentes de poder aquisitivo necessitadas de acompanhamento tanto médico, como psicológico, levando os profissionais a cometer distorções teóricas, práticas descontextualizadas, psicologizando as demandas sociais, ou seja, reproduzindo um velho dito popular "faça o que eu digo, mas não faça o que eu faço".

Nesta perspectiva, o modelo curativo e assistencialista, voltado para o setor dos atendimentos privados foi se consolidando dentro da categoria dos psicólogos, tornando-se o paradigma hegemônico da profissão, que prevaleceu em voga por 30 anos, aproximadamente. (Dimenstine, 2001) 
A partir das elucidações supracitadas pode-se afirmar que o profissional de Psicologia adentrou no contexto da saúde sem ter claro de que maneira iria atuar, sendo inicialmente subordinado do modelo biomédico passou a se perguntar qual manejo ou recurso psicoterapêutico seria o mais adequado para lidar com a saúde, a doença, o doente, a equipe e seus familiares? Existe diferença entre as categorias mencionadas? Um só recurso supre a necessidade das demandas? Qual o papel da família? Em meio a tantas indagações e demandas sociais contextualizadas no campo da saúde, esse profissional se viu limitado e passou a construir novas práticas voltadas a prevenção e produção social da saúde dos atores sociais, visando minimizar o sofrimento causado pelas adversidades sociais, situações de crises existenciais, dificuldade de interação entre as equipes e as díades médico-paciente, família-ente querido, paciente-equipe de saúde e médico-equipe de saúde.

Com a inserção do psicólogo na equipe multidisciplinar, sua atuação deixa de ser subordinada ao modelo biomédico e passa a ser centrada na experiência do paciente juntamente com sua doença, buscando entender o contexto social, o qual, este usuário da saúde se encontra inserido. De acordo com Spink (2003) a mudança de paradigma na saúde suscitou novos horizontes delineando o exercício do psicólogo nesse campo de atuação.

Deste modo, postula-se que a Psicologia da Saúde, vem construindo um novo saber, revelando uma nova perspectiva para a demanda social vigente, colocando na prateleira a prática clínica, fazendo uso dos recursos dessa apenas quando necessário. Entretanto, vale pontuar que a passagem do modelo biomédico que considerava a doença como unidimensional para uma visão multidimensional, reflete a necessidade de compreender o ser humano, isto é a pessoa que está doente, nos aspectos bio-psico-sócio-cultural e espiritual, como propõem a OMS ( 2001).

Neste direcionamento, advoga-se que as demandas atuais inseridas no campo da saúde coletiva, nos espaços hospitalares, ambulatoriais como os Programas de Saúde da Família PSF, os postos de saúde, Centros de Apoio Psicossocial - CAPS, entre outros clamam pela compreensão dos ambientes familiares e do processo migratório associados a dinâmica interna do adoecer.

Assim, processo migratório pode ser entendido como um complexo fenômeno social que envolve mudança não apenas de endereço, mas de toda uma série de contatos socioculturais do indivíduo nos diferentes contextos de sua vida, afirma Franco apud Ramos (2004). 
Deste modo, verifica-se a presença da família no processo da saúde-doença e prevenção do ator social. Como este contexto está sendo configurado? Qual a responsabilidade da família? E a do Estado? E a Psicologia, como pode atuar?

Com base em Ramos (2004) afirma-se que "a família desempenha um papel imprescindível na provisão de cuidado informal para os seus membros ,ou seja, é um cadinho responsável pelo desenvolvimento pessoal de cada integrante familiar”. A partir dessa vertente, o sentimento de pertencer a uma família, comunidade, e/ou cultura, dá a sensação de segurança interna que favorece o desenvolvimento da criança.

A autora antes mencionada considera que desde os primeiros tempos de vida, a proteção e a segurança emocional são elementos indispensáveis a saúde, as condições do desenvolvimento psíquico, físico e autônomo, através das rotinas diárias, dos cuidados repetidos, das práticas educativas e de proteção, efetivando um clima afetivo e social apropriado.

Frente a essa realidade, as relações afetivas estabelecidas entre os membros de uma família são indispensáveis para um desenvolvimento saudável dos atores sociais, visto que o ambiente familiar torna-se um espaço de troca, proporcionando interações sociais e comunicação de qualidade ou não entre os pares, o que viabiliza bases positivas e/ou negativas para a saúde mental e física da criança, que refletirá na aceitabilidade de regras e normatizações sociais.

Percebe-se que, a forma de como se encontra estruturada a família implicará no desenvolvimento da personalidade tanto da criança, quanto do adolescente. Ou seja, se esses atuam em um contexto desestruturado, sem um aparato condizente com as adversidades da realidade, consequentemente, os atores sociais refletirão fragilidades físicas, emocionais, sociais e comportamentais, possibilitando um crescimento em consonância com as demandas do meio.

Contudo, os diferentes processos de viver, adoecer, ou morrer, além das questões biológicas são determinados pelas condições de vida, de trabalho e relacionamentos dos atores sociais nas suas famílias.

Quanto ao papel do profissional de psicologia esse vem se fortalecendo na construção da saúde social, óbvio que em grau, freqüência e intensidade diferentes de acordo com cada espaço e demanda. A Psicologia perante tais temáticas tem assumido um papel de investigadora, observadora se atentando para a dinâmica da família. 
Desse modo tem buscado estratégias de intervenção por meio da compreensão do desempenho de papéis sociais assumidos por cada membro da família; das relações afetivas entre esses membros; entre outras temáticas.

No que refere-se ao contexto da migração, numerosas investigações têm mostrado que um certo número de sujeitos, separadas do seu grupo social e familiar, desenraizados e isolados, apresenta dificuldades de oferecer às crianças a mesma disponibilidade e riqueza de interações do seu meio de origem, essa condição na maioria das vezes, gera nos da família crise existencial, confusões de papéis, onde não há uma afirmação da identidade em relação ao novo contexto. De acordo com os estudos desenvolvidos por Ramos (1999; 2000; 2001), pode-se considerar que os migrantes constituem um grupo de risco ao nível da saúde mental e física.

\section{Considerações:}

Mediante a prática profissional e os levantamentos teóricos, verifica-se que a migração não está implicada apenas numa mobilização geográfica, mas na capacidade do sujeito desempenhar novas funções, assumir novos papéis sociais perante as exigências do cenário social.

Ademais, como a Psicologia enquanto ciência e profissão pode interferir frente as adversidades que o processo de aculturação provoca na dinâmica do adoecer?

O papel que o psicólogo pode exercer é o de agente de mudanças, facilitador, interlocutor nas relações sociais, entre as díades família-equipe de saúde, família-paciente, e paciente equipe de saúde?

Para exercer um papel pautado no novo paradigma da saúde, o psicólogo pode está resgatando a população migrante que tanto se anula atrás das suas dificuldades e adversidades cotidianas, colocando-a para atuar, e desempenhar diferentes papéis sociais a depender da sua demanda e necessidade.

Ao se pensar, nessa nova reconstrução de realidade, o psicólogo enquanto profissional engajado nas problemáticas sociais pode juntamente com o PSF (Programa de Saúde Familiar) trabalhar as representações sociais da população migrante, possibilitando a elaboração de novos valores e novos sentidos, ,contribuindo para uma atenção de qualidade na saúde associada a intervenção educativa, levando em consideração que a plasticidade dos seres humanos os permitem a se adaptarem às diferentes cenários sociais. 
Deste modo, o viés utilizado pelo psicólogo para apaziguar todas essas questões seria o uso de uma comunicação verbal e não-verbal acessível e compreensiva que não fosse agressiva, intimidadora, levando o sujeito a ter resistências, dificultando as relações com os contrastes e as controvérsias, não se encontrando enquanto um ser humano social.

Em suma, ao redigir essas palavras pensou-se em refletir, instigar debate acerca da temática, e lembrar que o papel do psicólogo da saúde transcende o processo saúde-doença, indo além, envolvendo relações interpessoais, processos de migração, e aculturação que refletem nos aspectos afetivos, cognitivos e comportamentais do sujeito que adoece.

\section{Referências:}

DIMENSTAINE, Magda. O psicólogo e o compromisso social no contexto da saúde coletiva. Psicologia em Estudo, Maringá, v. 6, n. 2, p. 57-63, jul./dez. 2001

ORGANIZAÇÃO MUNDIAL DE SAÚDE - OMS. Informe sobre la salud en el mundo. Salud mental: nuevos conocimientos, nuevas esperanzas. Ginebra: Organización Mundial de la Salud. 2001.

RAMOS, Natália. A educação da criança migrante. Uma abordagem intercultural. In: seminário Internacional: Migração e integração européia. Emprego, educação, cidadania e dinâmicas locais. Porto - Ptg, 20 e 21 de Nov. 1999.

RAMOS, Natália. Mulculturalidade, Migração e Cuidados na primeira infância. Perspectivas de prevenção em saúde mental precoce. In: Jornada Científica do Núcleo de Psiquiatria Transcultural. Lisboa, Hospital Miguel Bombarda. Portugal, 10 de Maio. 2000.

RAMOS, Natália. Comunicação, cultura e interculturalidade: Para uma comunicação intercultural. Revista Portuguesa de Pedagogia. 35. (2). pp. 155-178. 2001.

RAMOS, Natália. Psicologia Clínica e da Saúde. Lisboa - Ptg. Universidade Aberta, 2004

SPINK, M.J. P. Psicologia Social e Saúde; práticas, saberes e sentidos. Ed: Vozes. 2. ed: Petrópolis, RJ, 2003.

Sobre as autoras:

(1) Roseane C. da Nova de Sá é Mestre em Psicologia Social. Professora da Faculdade São Francisco de Barreiras - FASB, Consultora do Comitê de Ética em Pesquisa (CEP - FASB). E-mails: roseane@,fasb.edu.br / psicologiapb@yahoo.com.br Telefone: 7736138845 - Colegiado de Psicologia.

(2) Roberta Lima de Azevedo é Acadêmica do $6^{\circ}$ semestre de psicologia da FASB. E-mail: robertablue530@hotmail.com 